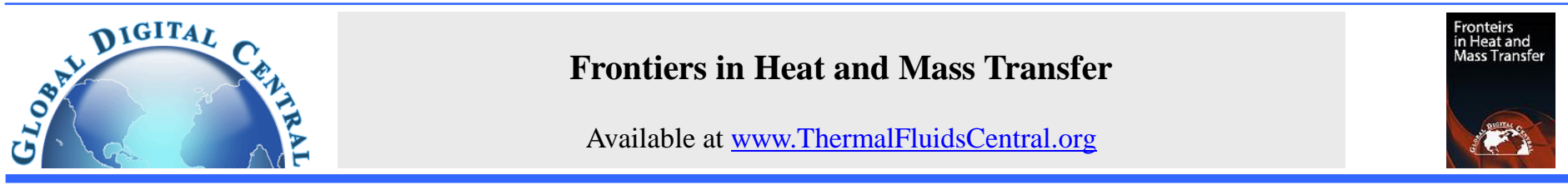

\title{
THERMOHYDRAULIC CHARACTERISTICS OF A SINGLE-PHASE MICROCHANNEL HEAT SINK COATED WITH COPPER NANOWIRES
}

\author{
M. Yakut Ali ${ }^{\mathrm{a},}$, Fanghao Yang ${ }^{\mathrm{a}}$, Ruixian Fang ${ }^{\mathrm{a}}$, Chen $\mathrm{Li}^{\mathrm{a}}$, and Jamil Khan ${ }^{\mathrm{a}, \dagger}$ \\ ${ }^{a}$ Department of Mechanical Engineering, University of South Carolina, Columbia, SC 29208, USA
}

\begin{abstract}
This study experimentally investigates single phase heat transfer and pressure drop characteristics of a shallow rectangular microchannel heat sink whose surface is enhanced with copper nanowires (CuNWs). The hydraulic diameter of the channel is $672 \mu \mathrm{m}$ and the bottom wall is coated with $\mathrm{Cu}$ nanowires (CuNWs) of $200 \mathrm{~nm}$ in diameter and $50 \mu \mathrm{m}$ in length. CuNWs are grown on the $\mathrm{Cu}$ heat sink by electrochemical synthesis technique which is inexpensive and readily scalable. The heat transfer and pressure drop results of CuNWs enhanced heat sink are compared with that of bare copper surface heat sink using deionized (DI) water as the working fluid at Reynolds Number (Re) ranging from 106-636. The experimental results indicate an enhancement in Nusselt Number $(\mathrm{Nu})$ at all Re with a maximum enhancement of $24 \%$ at $\mathrm{Re}=106$. An increase in pressure drop is also observed in all test cases due to enhanced roughness. The enhanced thermal performance is attributed to the enhanced wettability and the increased heat transfer surface area due to the addition of CuNWs arrays. The surface morphology of the heat sink has also been studied before and after heat transfer experiments through SEM to determine the effect of fluid flow on CuNWs arrays. The SEM results demonstrate no notable changes in surface morphology for the Re range in which experiments have been conducted and for single phase flow.

Keywords: Microchannel heat sink, Single phase, Copper nanowires
\end{abstract}

\section{INTRODUCTION}

Efficient, compact and cost-effective heat removal has become an important issue with the advancement and rapid growth of microelectronics industry due to increased integration density of chips in devices and the increased current and voltage handling capability of power electronic devices (Vafai, K. and Zhu, L., 1999). According to Moore's law, the number of functional units i.e. transistors in an electronic chip will double every two years (Moore, G.E., 1965). This implies that significantly enhanced heat dissipation per unit area will be required in future space constrained electronics devices, which may go beyond the capability of conventional cooling techniques. Hence, alternative cooling methods with high heat flux removal capabilities have been one of the main research focuses of thermal engineers in recent years.

Alternative competing thermal management solutions are reviewed extensively in reference (Garimella, S.V., 2006). The author identified the liquid-cooled microchannel heat sinks as one of the most effective and promising thermal management solutions due to their compact size, dense package, large amount of heat removal from a small area and larger surface area per unit volume. Generally microchannel heat sinks reported in literature consist of a single channel or closed parallel multichannel. The channels may be rectangular, trapezoidal, or triangular in cross sections having characteristic dimensions varying from 100 to $1000 \mu \mathrm{m}$. Microchannel heat sinks can either be singlephase or two phase. In case of single phase heat sink, the coolant takes the heat in form of sensible heat gain from the chip. Whereas, in case of two-phase heat sink the latent heat of the coolant during boiling comes into play as well (Garimella, S.V. et al., 2006). Extensive experimental and theoretical investigations (Phillips, R.J., 1987; Qu W,. and Mudawar, I., 2002; Harms, T.M. et al., 1999; Lee, P.S. et al., 2005; Morini, G.L., 2004) have been carried out by several researchers to explore single phase and two phase microchannel heat transfer since the pioneering work by Tuckerman and Pease (Tuckerman, D.B. et al., 1981).

Enhancing the microchannel heat transfer is of importance to meet the ever increasing heat dissipation of electronics chip. Augmentation of the single phase microchannel cooling will extend its applicability in critical applications before considering more aggressive techniques (e.g. flow boiling), but requires a great deal of research (Steinke, M.E., Kandlikar, S.G., 2004).

Advancement in nanotechnology offers some potential and innovative thermal management solutions by using one dimensional (1D) nanostructures i.e. nanowires, nanorods and nanotubes on heat transfer surface. Significant and striking enhancement in case of conventional scale pool boiling heat transfer using $\mathrm{Si}$ and $\mathrm{Cu}$ nanowires (Chen, R. et al., 2009), $\mathrm{Cu}$ nanorods (Li, C. et al., 2008) and flow boiling enhancement using carbon nanotubes (CNTs) (Singh, N. et al., 2010) have been reported very recently. The reason of dramatic enhancement has been attributed to the several unique properties of nanostructures- improvement of surface wettability, enhancement in heat transfer area, and high nucleation site density.

\footnotetext{
* Currently in the Department of Mechanical Science and Engineering at University of Illinois at Urbana-Champaign, Urbana, IL 61801, USA

† Jamil Khan.Email:khan@cec.sc.edu
} 
The applicability of 1D nanostructures in microchannel heat sink for enhanced thermal performance is yet to be realized. Only two experimental (Dietz, C.R., 2007; Khanikar, V. et al., 2009) and one numerical work (Dixit, P. et al., 2008) have been reported from which no clear conclusion can be drawn on enhancement potential of 1D nanostructures. Carbon nanotubes (CNTs) coated singe phase (Dietz, C.R., 2007) and two phase microchannel (Khanikar, V. et al., 2009) shows reduced thermal performance compared to bare/uncoated microchannel heat sink. In both cases, CNTs were grown on heat sink using chemical vapor deposition (CVD) process. In case of single phase, the hydrophobic nature of CNT arrays have been assumed to be responsible for reduced thermal performance. Whereas in case of two phase, notable change in the surface morphology of CNT arrays at higher flow velocities compromised the 'fin effect' reducing the initial enhancement of critical heat flux at low flow velocities.

Only enhancement (approximately 16\%) reported in single phase microchannels is the Si nanopillars based multilayered heat sink (Dixit, P. et al., 2008) but still lacks experimental evidence. In their work, Dixit et al. presented a multilayered water cooled microchannel heat sink concept where Si nanopillars are grown in the microchannels by utilizing the micromasking effects in deep reactive ion etching (DRIE). The authors experimentally demonstrated the feasibility of their concept by growing Si nanopillars in microchannels. The thermal performance of the heat sinks has been evaluated by developing a simple thermal resistance model and has been compared with a heat sink without $\mathrm{Si}$ nanopillars. The analytical analysis shows better thermal performance (as much as $16 \%$ improvement) of the nanopillar based microchannel heat sink.

It is noteworthy to mention that although the $\mathrm{Cu}$ nanowires show the best performance in case of pool boiling experiments, no experimental or modeling efforts have been made to assess its effect on microchannel heat sink performance to our knowledge and uncover the mechanisms of expected enhancement. $\mathrm{Cu}$ nanowires are a unique class of materials that can offer several advantages which can be beneficial for enhancing single phase microchannel heat transfer:

- Surface modification by increasing the surface roughness

- Improvement of surface wettability characteristics

- High surface area to volume ratio providing 'fin effect'

In the present work, we focus on the assessment of thermal performance of rectangular microchannel heat sink whose bottom surface is modified using $\mathrm{Cu}$ nanowires (CuNWs). CuNWs have been chosen because of their excellent performance reported in pool boiling experiments and ease of synthesis on $\mathrm{Cu}$ heat sink using template based electrochemical synthesis technique which is inexpensive, reliable, and easily scalable.

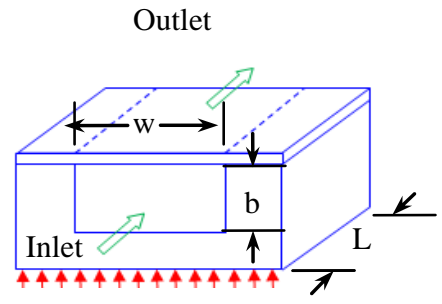

(a)
Heat Flux from Bottom

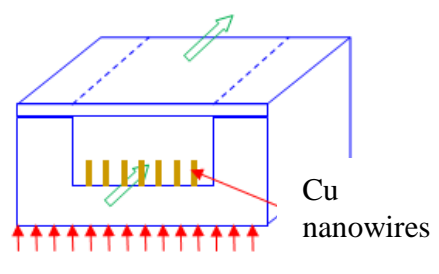

Heat Flux from Bottom

(b)
Fig. 1 Schematic diagram showing the concept of (a) Bare Microchannel Heat Sink, (b) $\mathrm{Cu}$ nanowires on the bottom of microchannels.

In this study, for different $\mathrm{Re}$ in the laminar region, the heat transfer (in terms of $\mathrm{Nu}$ and $h$ ) and pressure drop characteristics of a shallow rectangular microchannel with CuNWs coatings on the bottom wall have been experimentally evaluated. The experimental results have also been compared with those of a bare $\mathrm{Cu}$ heat sink using DI water as the working fluid. A conceptual schematic of the proposed work is displayed in Figure 1. To the best of our knowledge, this is the first investigation to evaluate the thermal performance of $\mathrm{CuNWs}$ coated microchannels. To assess the effect of fluid flow on nanostructures, SEM images have been also taken on the CuNWs coated interfaces before and after the heat transfer tests. In addition, surface wettability characteristics of both heat sinks have been measured and compared. The experimental results demonstrate a significant improvement in surface wettability, enhanced thermal performance and increased pressure drop for the CuNWs enhanced heat sink compared to bare heat sink in all test cases performed. This investigation may lead to the development of nanowires-enhanced single-phase and two-phase microchannel thermal management technologies.

\section{EXPERIMENTAL STUDY}

\subsection{Water Flow Loop}

The schematic of the water flow loop facility used in this study is shown in Figure 2. The water flow loop was configured to supply working fluid (DI water) to the microchannel test section at the desired flow rate and pressure. A gear pump (Ismatec Reglo-z Digital) was used to drive the DI water at a constant flow rate to the test section. The DI water was degassed and filtered before entering the test section using venturi vacuum pump (Cole-Parmer) in conjunction with a Minimodule $^{\mathrm{TM}}$ Membrane Contractors. Warm water from the exit of microchannel test section was collected into a container put on a high precision balance, which is employed to calibrate the mean flow rate. The open flow loop was used to visually inspect the presence of CuNWs (if any) in exit water at the exit reservoir.

\subsection{Test section}

The details of the test section assembly are displayed in Figure 3. It comprises a cover plate, a housing, a copper heat sink, a cartridge heater, insulation blocks and a support plate. The design is referred to the similar part of (Qu, W. and Mudawar, I., 2002).

The heat sink part was fabricated on a single copper block. The copper was an Oxygen-free electronic alloy number C10100. It has a thermal conductivity of $391 \mathrm{~W} / \mathrm{m} \cdot \mathrm{K}$ at room temperature. The top surface of the copper block measured $5 \mathrm{~mm}$ in width and $26 \mathrm{~mm}$ in length. A single shallow rectangular microchannel was formed by inserting the copper block into the centre cavity of the housing as shown in Figure 3(a) and 3(b). The channel dimensions and other parameters for each test case are listed in Table 1

Table 1 Microchannel dimensions and test cases

\begin{tabular}{|c|c|c|c|c|c|c|}
\hline$\#$ & $R e$ & $\begin{array}{c}w \\
(\mathrm{~mm})\end{array}$ & $\begin{array}{c}b \\
(\mu \mathrm{m})\end{array}$ & $\begin{array}{c}L \\
(\mathrm{~mm})\end{array}$ & $\begin{array}{c}D_{h} \\
(\mu \mathrm{m})\end{array}$ & $\alpha=w / b$ \\
\hline 1 & 106 & 5 & 360 & 26 & 672 & 13.89 \\
\hline 2 & 208 & 5 & 360 & 26 & 672 & 13.89 \\
\hline 3 & 316 & 5 & 360 & 26 & 672 & 13.89 \\
\hline 4 & 428 & 5 & 360 & 26 & 672 & 13.89 \\
\hline 5 & 529 & 5 & 360 & 26 & 672 & 13.89 \\
\hline 6 & 636 & 5 & 360 & 26 & 672 & 13.89 \\
\hline
\end{tabular}

Six holes with diameter of $0.85 \mathrm{~mm}$ were drilled into the side wall of the copper heat sink at a distance $2.5 \mathrm{~mm}$ below the top surface and up to the half width (centre plane) of the copper block. In order to measure the heat sink's stream-wise temperature distribution, six chromel- alumel (type-K) thermocouples (from Omega Engineering Inc.) with a $0.8 \mathrm{~mm}$ bead diameter were inserted into these holes. The thermocouple locations, as measured from the inlet of the microchannel and along its length, were $4 \mathrm{~mm}, 7 \mathrm{~mm}, 10 \mathrm{~mm}, 14 \mathrm{~mm}, 19 \mathrm{~mm}$, and 24 $\mathrm{mm}$. These thermocouple temperature readings were extrapolated to 


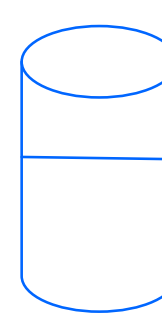

Liquid Reservoir

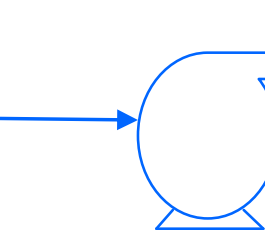

Gear Pump

Degasifier and Filter

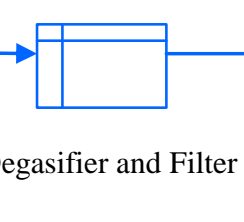

\section{Control Valve}

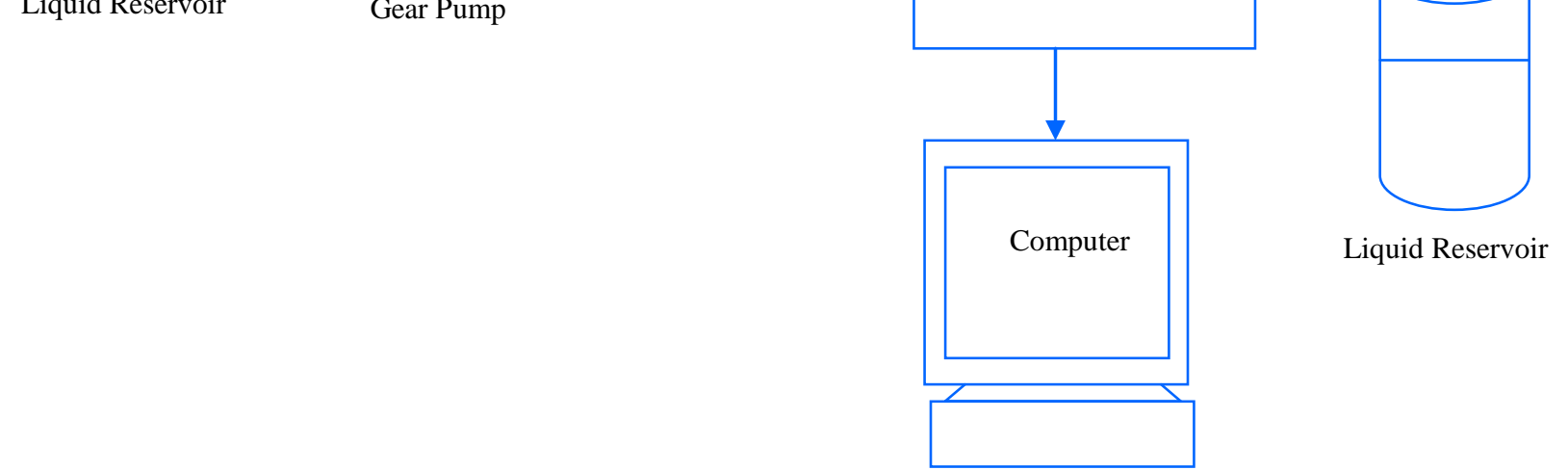

Fig. 2 Schematic diagram of the water flow loop.

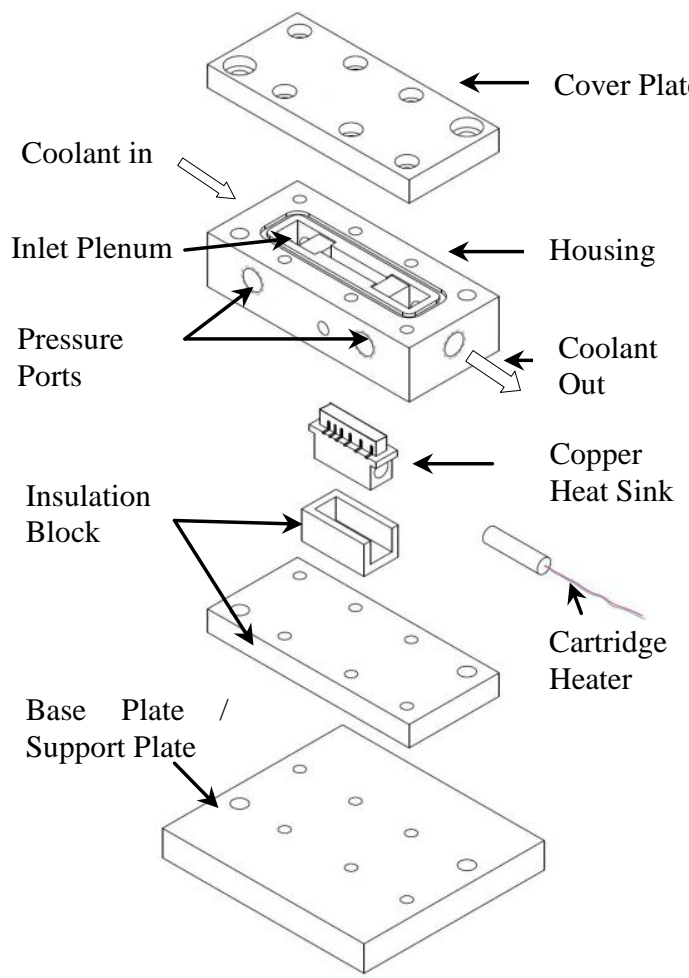

obtain the microchannel wall temperature. Two type-K thermocouples were placed in the inlet and outlet plenum to measure the channel inlet and outlet water temperatures respectively. All thermocouples were read into a NI cDAQ-9172 data acquisition system.

A small protruding platform was machined around the periphery of the heat sink beneath the thermocouple holes to aid accurate positioning of the heat sink in the housing as well as providing sufficient area for water tight sealing. Below the platform, a $6.35 \mathrm{~mm}$ diameter through hole was drilled along the length of the cooper block to accommodate the cartridge heater. The resistive cartridge heater was powered by a DC power supply unit and provides a uniform heat flux to the copper block. The power supplied to the cartridge heater was calculated as the product of voltage and current. The housing part was

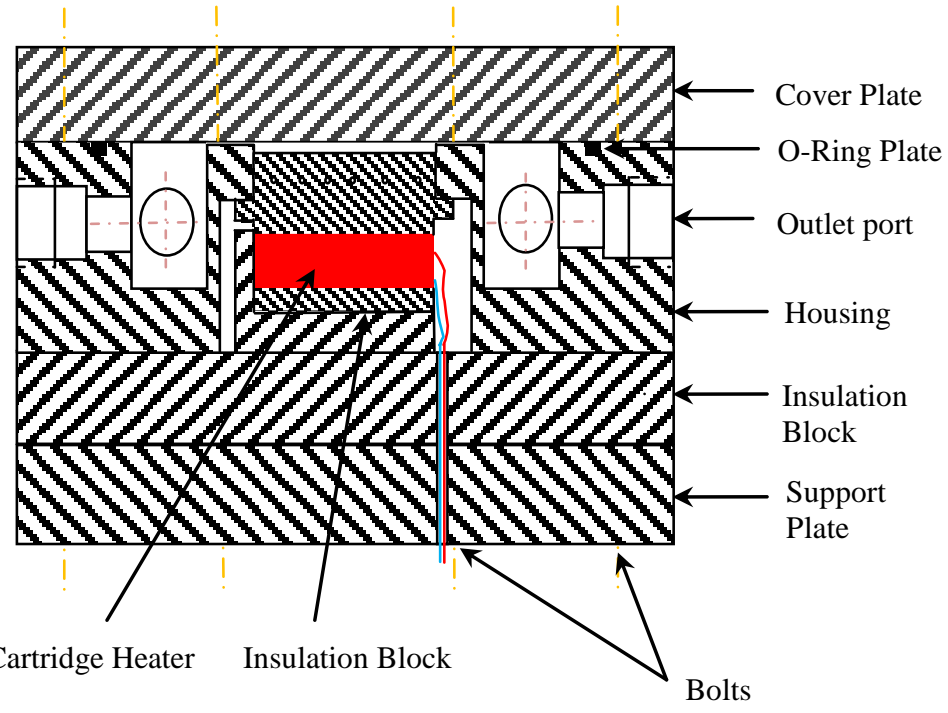

(b)

Fig. 3 (a) Exploded view of the main components of the test section, (b) Assembly of the test section.

made from high temperature polycarbonate plastic (Lexan). The material from the central part of the housing was removed where the heat sink could be inserted. RTV silicon rubber was applied along the mating surfaces of the housing and the heat sink to establish a watertight seal. Two absolute pressure transducers (Omegadyne PX309) were connected to the deep portion of inlet and outlet plenums via pressure ports to measure the inlet and outlet pressure, respectively. The pressure transducers were connected to the NI cDAQ-9172 data acquisition system as well.

The cover plate made from transparent polycarbonate plastic was bolted atop the housing. The cover plate and the housing along with copper heat sink top surface formed the closed microchannel as shown in Figure 3. An O-ring maintained a leak-proof assembly in the 
housing. The insulator block was placed on the heat sink to reduce heat loss. The bottom support plate was also made from polycarbonate plastic (Lexan).

\subsection{Synthesis and Characterization of CuNWs on Cu heat sink}

In this study, copper nanowires on the copper heat sink were fabricated by template based electrochemical synthesis technique (Gao, T. et al., 2002). This synthesis method was used as it is inexpensive and readily scalable. Scanning electron microscopy (SEM) was used to characterize the copper nanowires.

(1)

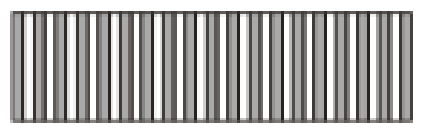

(2)

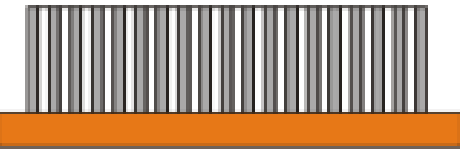

(3)

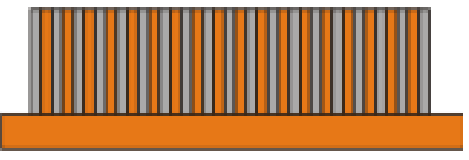

(4)

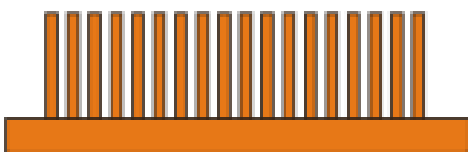

(a) methacrylate/plexiglass) with copper foil on it, the intermediate plate (made of polymethyl methacrylate), the $\mathrm{Cu}$ heat sink, a rubber cushion, the PAA template and Whatman Grade No. 41 filter paper premoistened with aqueous $\mathrm{CuSO}_{4}$ and $\mathrm{H}_{2} \mathrm{SO}_{4}$ solution, another copper foil and top plate (made of polymethyl methacrylate).

The bottom/base plate was made of plexiglass (polymethyl methacrylate) and a $\mathrm{Cu}$ foil was placed on top of it. During assembly, it had been made sure that this $\mathrm{Cu}$ foil was in contact with the $\mathrm{Cu}$ heat sink. The base plate had an opening at centre (not through) to accommodate the lower part of the $\mathrm{Cu}$ heat sink.

The intermediate plate (also made of plexiglass) was used to hold

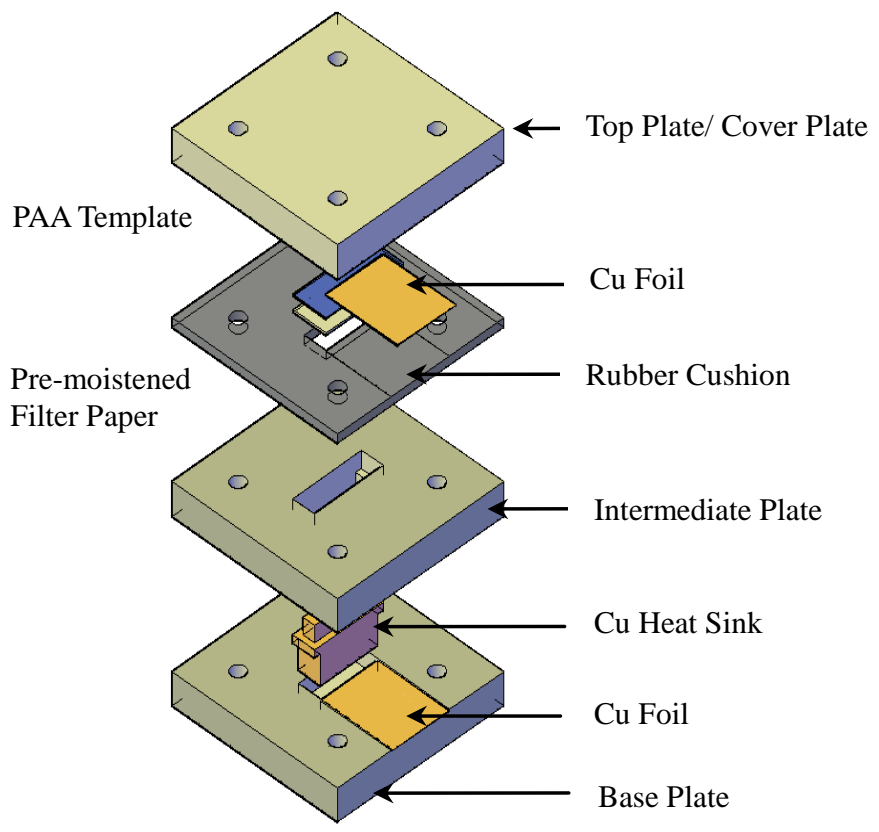

(b)

Fig. 4 (a): Schematic illustration of $\mathrm{Cu}$ nanowires synthesis steps (1) PAA membrane used as template (2) PAA template placed on flat Cu heat sink (3) Electrochemical deposition of copper in the nanochannels (4) Removal of PAA template by using $\mathrm{NaOH}$ solution leaving the Cu nanowires. (b): Reactor components schematic. The assembly of the reactor is done with the components bolted atop. The copper film which is attached to the base plate touches the $\mathrm{Cu}$ heat sink and thus serves as a working electrode for electroplating process (for details, see the text).

Template based synthesis has been accepted as a versatile approach for the synthesis of $1 \mathrm{D}$ nanostructures since the pioneering research of Martin's group (Martin, C.R., 1994; Brumlik, C.J. et al., 1994). Electrochemical deposition (ECD) is easily controllable and inexpensive in terms of cost, and thus offers great opportunities for the synthesis of new nanostructures (Zach, M.P. et al., 2000; Lu, L. et al., 2000; Switzer, J.A., 1999).

Figure 4(a) illustrates the basic steps for the fabrication of $\mathrm{Cu}$ nanowires by electrochemical synthesis technique. The porous anodic alumina (PAA) template is placed on flat and smooth $\mathrm{Cu}$ substrate on which $\mathrm{CuNW}$ s need to be grown. The $\mathrm{Cu}$ substrate itself can work as working electrode (cathode). Using aqueous $\mathrm{CuSO}_{4}$ and $\mathrm{H}_{2} \mathrm{SO}_{4}$ solution as electrolyte and a $\mathrm{Cu}$ foil as counter electrode (anode), an electrical potential is applied across the two electrodes. When the electro deposition is completed (the amount of deposition depends on the magnitude of electrical potential and the time duration of the applied potential), the PAA template is then removed by using $\mathrm{NaOH}$ solution. After that step, the sample is further rinsed in DI water and dried in an inert environment.

Due to the design of heat sink (referred to Section 2.2), a special reactor as displayed in Figure 4(b) was made in this study to ensure the uniform growth of $\mathrm{Cu}$ nanowires along the heat transfer surface area. The reactor consisted of a base plate (made of polymethyl the upper part of the heat sink in position. The material from the central part was removed so that the heat sink could easily go through it. After the heat sink was placed in position, the rubber cushion was placed over the intermediate plate to ensure proper gripping between the top plate and intermediate plate. The material from the central part of the rubber cushion was removed in such a manner that the top surface of the heat sink remained uncovered.

In the present study, $60 \mu \mathrm{m}$ thick membranes with $200 \mathrm{~nm}$ nominal pore size and approximately $50 \%$ nominal porosity from Whatman Inc. were used as the templates for $\mathrm{Cu}$ electroplating. The PAA template was placed on the top surface of the heat sink on which nanowires need to be synthesized. Above the template, a Whatman Grade No. 41 filter paper (soaked in aqueous $\mathrm{CuSO}_{4}$ and $\mathrm{H}_{2} \mathrm{SO}_{4}$ solution) was placed.

Another copper foil was placed on the filter paper. This foil worked as counter electrode during the electrodeposition process. The assembly of the reactor was completed with the top plate (also made of plexiglass) placed on the foil and bolted atop.

A CH Instrument electrochemical workstation was used to provide a stable voltage of $-0.3 \mathrm{~V}$ for 60 minutes at room temperature. After the deposition is complete, the sample was put in $5-10 \% \mathrm{NaOH}$ solution for 2 hours to remove the PAA template and filter paper leaving the free standing $\mathrm{Cu}$ nanowires. The surface was further rinsed by DI water and the heat sink was dehydrated in a vacuum oven. 
SEM was used to characterize the obtained $\mathrm{Cu}$ nanowires. A FEI Quanta 200 SEM was used to obtain the images. The SEM images obtained for both the bare $\mathrm{Cu}$ heat sink and the heat sink with $\mathrm{Cu}$ nanowires are shown in Figure 5.

The obtained $\mathrm{Cu}$ nanowires were $200 \mathrm{~nm}$ in diameter and $50 \mu \mathrm{m}$ in length. It is worth mentioning that there were microscale defects naturally formed within the nanowire arrays as shown in Figure 5(b) and (c). The formation of these cavities is presumably due to the surface tension of water during the drying process of nanowire synthesis, which pulls nanowires together to form bundles of wires and microscale cavities between them.

\subsection{Data acquisition}

A NI Compact DAQ-9172 data acquisition system was employed to record signals from the two pressure transducers and eight K-type thermocouples. For the eight thermocouples two NI 9211 DAQ card and for the two pressure transducers one NI 9203 DAQ card was used. The system communicated with a computer via a USB interface. A program written in LabVIEW software was used for all data acquisition. The sample rate for the thermocouples was $1 \mathrm{~Hz}$ and $1 \mathrm{KHz}$ for the two pressure transducers.

\subsection{Data postprocessing}

The steady-state sensible heat gain $q$ by the coolant can be determined from an energy balance:

$q=\rho \cdot C_{p} \cdot Q\left(T_{0}-T_{i}\right)$

Where the volumetric flow rate $Q$ was measured from the set value in gear pump control panel which is calibrated using a digital scale and stopwatch. The inlet and outlet fluid temperatures $\left(T_{o}\right.$ and $\left.T_{i}\right)$ were obtained using the two thermocouples positioned at the inlet and outlet plenum respectively. The density $(\rho)$ and specific heat $\left(C_{p}\right)$ were obtained at the mean fluid temperature Tm (average of the $T_{i}$ and $T_{o}$ ).

The power input $P$ to the cartridge heater was calculated as follows:

$$
P=V \cdot I
$$

Where, $V$ and $I$ were voltage and current readings respectively. In general, $80-90 \%$ of the power provided to the cartridge heaters was transferred to the water. For example, out of the $13.02 \mathrm{~W}$ power dissipated by the cartridge heaters in Test \#1 (at $R e=106$ ), $10.92 \mathrm{~W}$ was transferred to the coolant. Therefore, the effective average heat flux based on the base area $\left(q^{\prime \prime}=q /(L \cdot w)\right)$ was calculated using the measured sensible heat gain in Eq. (1). An average heat flux at the base was maintained for all $R e$.

The average heat transfer coefficient was determined from the basic convective heat transfer equation shown in Eq. (3).

$$
h=\frac{q}{A_{h t} \cdot \Delta T_{L M T D}}
$$

Where q was the heat gain by the coolant calculated from Eq. (1), $A_{h t}$ was the heat transfer area, and $\Delta T_{L M T D}$ was the log mean temperature difference given by Eq. (4).

$$
\Delta T_{\text {LMTD }}=\frac{\left(T_{s}-T_{i}\right)-\left(T_{s}-T_{o}\right)}{\ln \left(\left(T_{s}-T_{i}\right) /\left(T_{s}-T_{o}\right)\right)}
$$

Where $T_{s}$ was the surface temperature, $T_{i}$ was the inlet fluid temperature, and $T_{o}$ was the outlet fluid temperature. $T_{i}$ and $T_{o}$ were obtained from the average readings of inlet/outlet thermocouples. $A_{h t}$ was the microchannel bottom wall surface area.

As direct measurements of the microchannel wall surface temperature were not available, the microchannel surface temperature $T_{s}$ was determined from the thermocouple readings from Eq. (5).

$T_{S, j}=T_{c, j}-\frac{s \cdot q^{\prime \prime}}{\mathrm{k}_{\mathrm{Cu}}}$
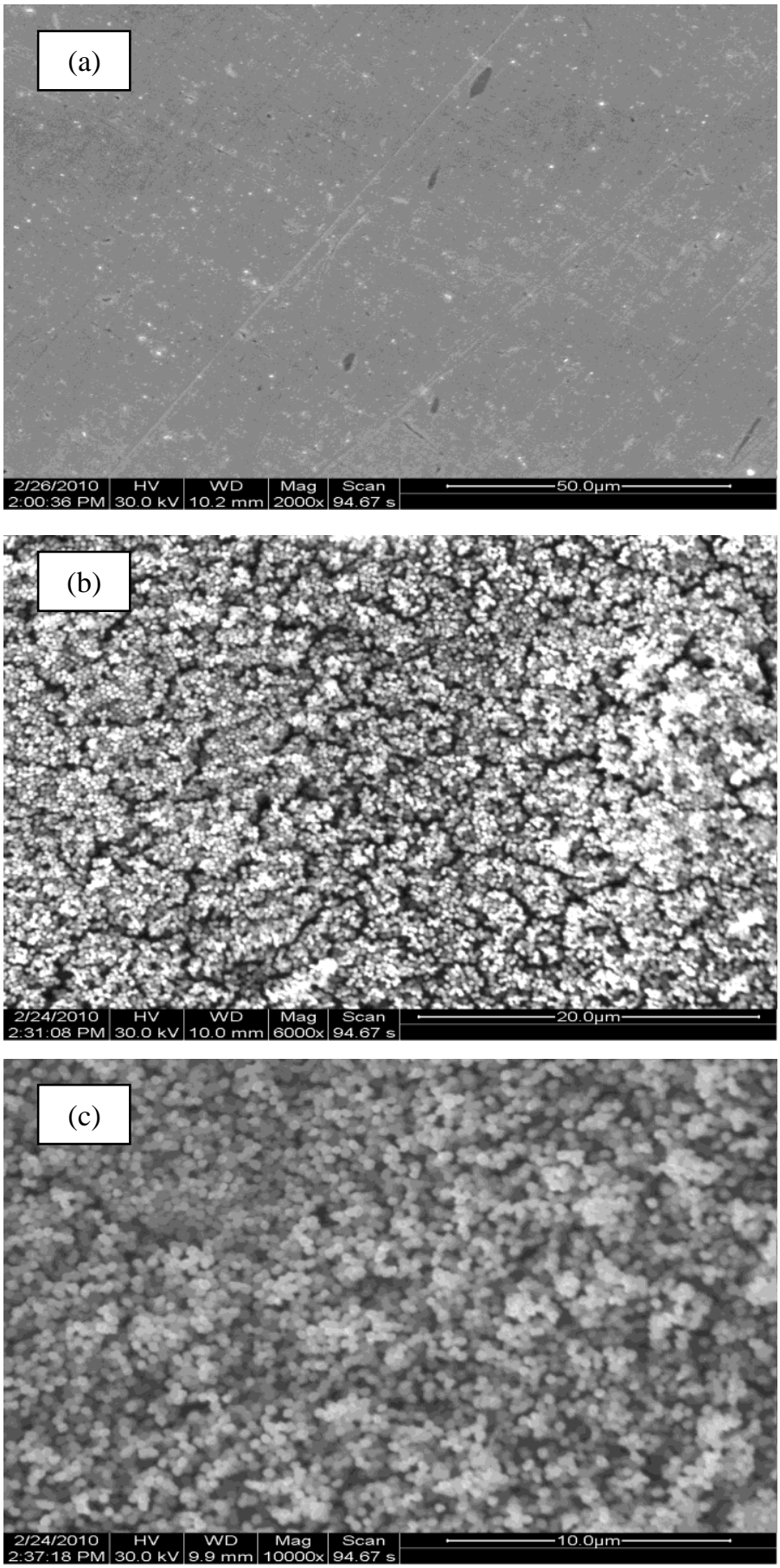

Fig. 5 SEM images of (a) Bare $\mathrm{Cu}$ heat sink and (b) and (c) $\mathrm{Cu}$ nanowires on the heat sink.

Where $T_{s, j}$ was the local wall surface temperature corresponding to the imbedded thermocouples, $T_{j}$ was each thermocouple reading, $\mathrm{s}$ was the distance from the thermocouples to the microchannel bottom wall surface, which was $2.5 \mathrm{~mm}$ in this case, $k_{C u}$ was the copper thermal conductivity, and $T_{s}$ was the average of $T_{s, j}$. Due to the high thermal conductivity of copper, the uncertainty involved with such an estimation of the wall temperature is low.

Finally, the corresponding average Nusselt number was obtained from Eq. (6).

$$
N u=\frac{h D_{h}}{k_{f}}
$$


In which the thermal conductivity $k_{f}$ of water was evaluated at the mean fluid temperature, and $D_{h}=0.672 \mathrm{~mm}$ which was calculated based on the Eq. (7).

$D_{h}=\frac{4 A_{c}}{P_{w}}$

Where $A_{c}$ was the flow cross-sectional area and $P_{w}$ was the wetted perimeter.

The Reynolds number was calculated using the following equation and based on the inlet parameters.

$\operatorname{Re}=\frac{\rho v D_{h}}{\mu}=\frac{\rho Q D_{h}}{A_{c} \mu}$

Where $\rho$ and $\mu$ were density and dynamic viscosity of the fluid respectively based on inlet properties. $v$ was the inlet velocity which is equal to $Q / A_{c}$.

With DI water as the working fluid, the investigations performed in this study fall into a hydrodynamically developed but thermally developing (TD) regime except the first test case $(R e=106)$ where the flow was fully developed in the downstream, using the criteria that $x^{+}=$ $L /\left(D_{h} R e\right)$ and $x^{*}=L /\left(D_{h} R e P r\right)$ should take values greater than 0.05 for fully developed conditions to be achieved. For all test cases, the values of $x^{+}$and $x^{*}$ are listed in Table 2 .

Table 2 Values of $\mathrm{x}^{+}$and $\mathrm{x}^{*}$ at different test cases

\begin{tabular}{|l|l|l|l|l|l|l|}
\hline $\operatorname{Re}$ & 106 & 208 & 316 & 428 & 529 & 636 \\
\hline$x^{+}$ & 0.363 & 0.186 & 0.123 & 0.09 & 0.073 & 0.060 \\
\hline$x^{*}$ & 0.067 & 0.032 & 0.021 & 0.015 & 0.012 & 0.010 \\
\hline
\end{tabular}

For calculating the friction factor $\mathrm{f}$, the following formula had been used:

$f=\frac{2 \Delta P D_{h}}{\rho L v^{2}}$

Where $\Delta p$ was experimentally measured pressure drop, $D_{h}$ was the hydraulic diameter calculated using Eq. 7. The water density $\rho$ had been calculated at $T_{m}$ and $v$ was the inlet velocity which was equal to $Q / A_{c}$.

\subsection{Experimental procedure}

The experiment procedure was followed for conducting each tests is described here. Once the test section was assembled and ready for investigation, the flow loop was evacuated and fluid was degassed. Then, the desired flow rate was set in the Gear pump control panel. The flow rate was also calibrated by collecting the water from microchannel test section exit. The heater power supply was switched on when a steady flow rate was achieved. The desired power input level was adjusted by adjusting the input voltage from DC power supply, and a steady state was usually reached in 90-120 minutes. The steady state was considered to be achieved when the thermocouple readings did not change with time i.e. the deviation was no more than $0.2^{\circ} \mathrm{C}$ for at least over a 5 min time period. A customized LabVIEW program was used as the data acquisition system and to monitor temperatures of all of the thermocouples and pressure transducers during tests. Once the steady state was achieved, the temperature readings of the thermocouples were documented. The pressure transducer readings, flow rate and heating power were also recorded when the steady state was achieved. The recordings were repeated for 3 times with a 10-15 minutes time interval. For each test case with nanowires coated heat sink, the identical flow rate and power input to the test section and cartridge heater respectively were repeated as in the case of bare copper heat sink for comparison. The experiments were conducted over the nominal Reynolds number range of 106-636.

\subsection{Uncertainty analysis}

Measurement uncertainties of pressure transducer, thermocouple, voltage measurement and current measurements were $0.25 \%, \pm 0.2^{\circ} \mathrm{C}$, $\pm 0.01 \mathrm{~V}$, and $0.4 \%$ respectively. The gear pump maintained than 0.1 $\%$ repetitive error in experimental flow rate range.

The uncertainty of a calculated parameter was obtained based upon the uncertainty in measured variables using the following equation from (Kline, S.J. and McClintock, F.A., 1953):

$U_{p}=\sqrt{\left(\sum_{i=1}^{n} \frac{\partial p}{\partial a_{i}} u_{a i}\right)^{2}}$

where $U_{p}$ is the uncertainty in calculated parameter $p, a_{i}$ are the variables of functional dependence and $u_{a i}$ is the uncertainty associated in the measurement of each $a_{i}$. Using this formula the uncertainties in different calculated parameters are shown in Table 3.

Table 3 Uncertainty in different calculated parameters

\begin{tabular}{|l|l|}
\hline Parameter & Uncertainty \\
\hline$D_{h}$ & $3 \%$ \\
\hline$R e$ & $5 \%$ \\
\hline$q$ & $6 \%$ \\
\hline$P$ & $1 \%$ \\
\hline$\Delta T_{L M T D}$ & $9 \%$ \\
\hline$h$ & $11 \%$ \\
\hline$N u$ & $12 \%$ \\
\hline$X^{+}$ & $5 \%$ \\
\hline$x^{*}$ & $5 \%$ \\
\hline
\end{tabular}

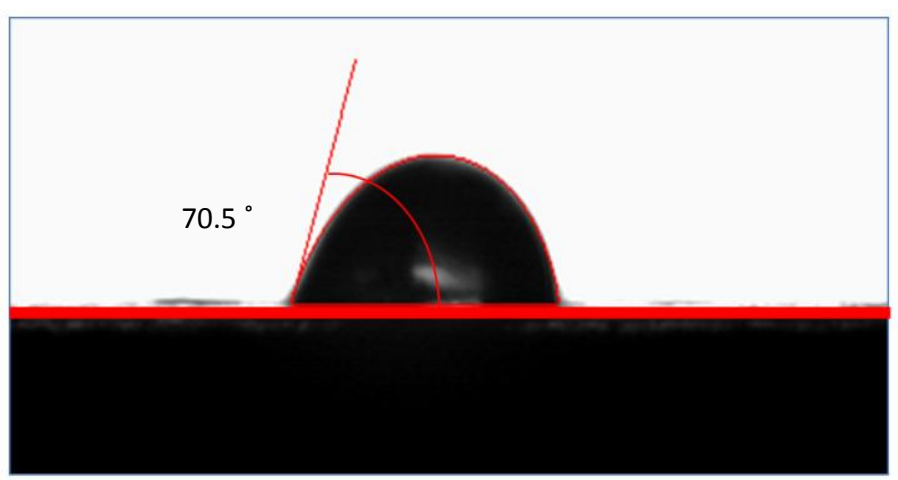

(a)

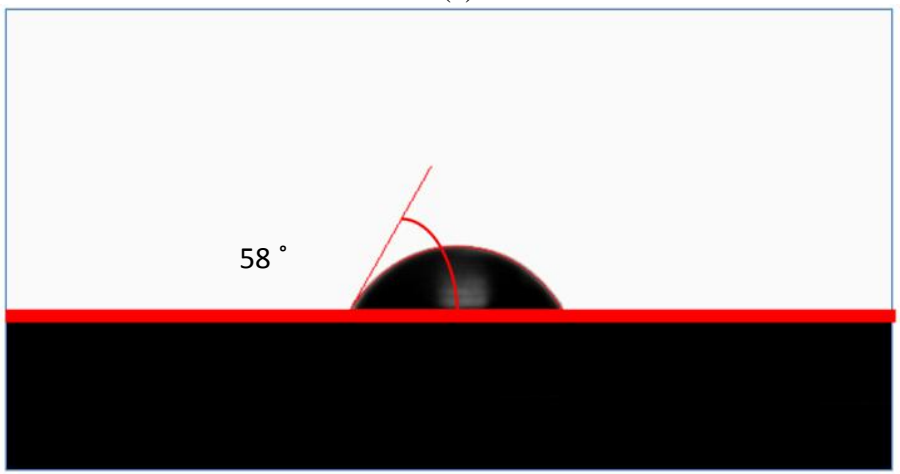

(b)

Fig. 6 Static contact angle measurements on (a) Bare Copper Heat Sink and (b) CuNWs coated heat sink. Results show a reduction in contact angle from $70.5^{\circ}$ to $58.0^{\circ}$ and hence improvement in surface wettability.

\section{EXPERIMENTAL RESULTS AND DISCUSSIONS}

\subsection{Surface wettability characteristic results}

The surface wettability characteristics for both bare $\mathrm{Cu}$ heat sink and nanowires coated heat sink were quantified. To perform the static contact angle measurements, a VCA Optima Surface Analysis System from AST Products Ltd. had been used. $0.25 \mathrm{ml}$ droplets of DI water 
were deposited on the surfaces and the static contact angles were measured. The results are displayed in Figure 6. The results indicate a reduction in the macroscopic water contact angle from approximately $70.5^{\circ}$ to $58.0^{\circ}$ due to the enhanced roughness (Kim, J. et al., 2006) caused by nanostructures.

\subsection{Heat transfer results}

Variation of Average Number (Nu) with Reynolds Number (Re) The variation of the average Nusselt number $(\mathrm{Nu})$ as a function of Reynolds number $(R e)$, for both the bare microchannel heat sink and CuNWs coated heat sink is presented in Figure 7. In addition to the experimental results, recently reported results with bare rectangular microchannels (Harms, T.M. et al., 1999) are also shown.

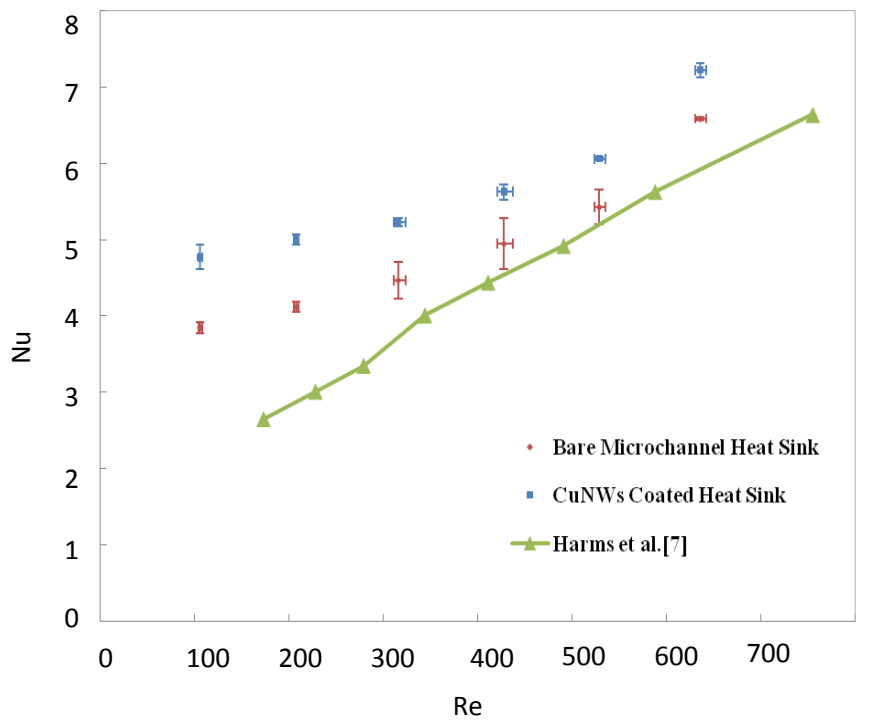

Fig. 7 Comparison of Nusselt number as a function of Re both for bare heat sink and CuNWs coated heat sink. Also, recent experimental results with bare Si microchannels [7] are also plotted.

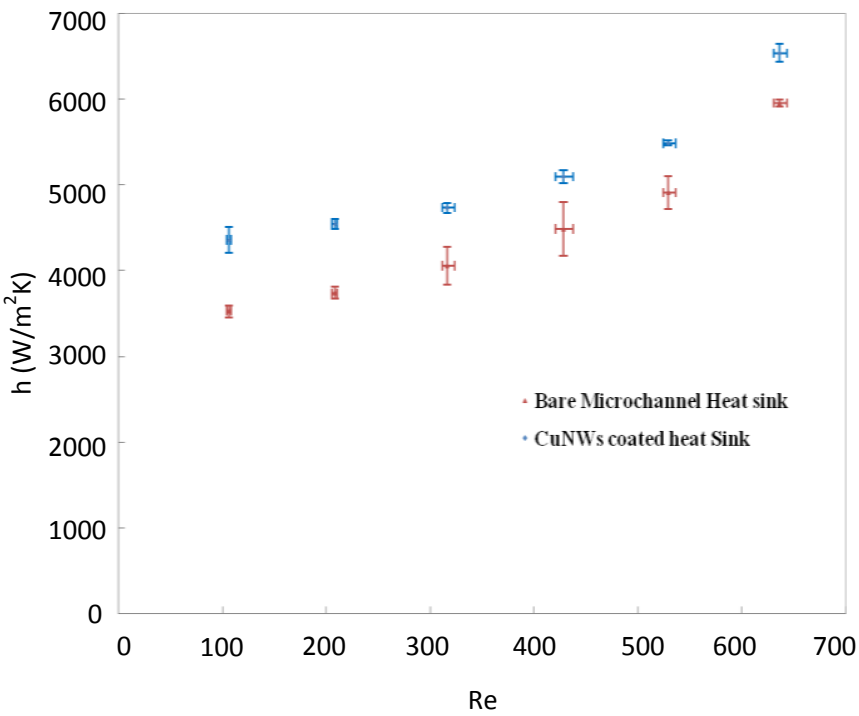

Fig. 8 Comparison of $\mathrm{h}$ as a function of Re both for bare heat sink and CuNWs coated heat sink. Results indicate an enhancement in h over the entire experimental Re range.

From the experimental results for the bare heat sink, it is clear that $\mathrm{Nu}$ increases with $\mathrm{Re}$ as expected. The $\mathrm{Nu}$ is not a constant value as in the case of fully developed laminar flow in conventional scale as all the test cases are in thermally developing regime except the first one where the flow has reached fully developed condition at downstream. The experimental work at (Harms, T.M. et al., 1999) was performed with rectangular multi microchannels on $\mathrm{Si}$ substrate. The deviations in experimental results from (Harms, T.M. et al., 1999) is attributed to the difference in aspect ratio, the heat sink material and the boundary conditions. The microchannel work has been performed with three sides heated (with adiabatic top wall) channel. In the current experimental study, the rectangular microchannel is heated from bottom only. The author had to adopt this design to allow the uniform growth of CuNWs on the heat transfer surface. Each test case was repeated six times and the maximum standard deviation is approximately $2 \%$ at the lowest $R e$ $=106$.

The comparison of average $\mathrm{Nu}$ as a function of Re between bare and $\mathrm{Cu}$ nanowires coated heat sink reveals that for all test cases the experimentally determined $\mathrm{Nu}$ number is higher for $\mathrm{CuNW}$ s coated heat sink compared to that of the bare heat sink. However, one interesting phenomenon observed is that the percentage enhancement decreases as the $R e$ increases. At $R e=106$ the results demonstrate a maximum of $24 \%$ enhancement in $\mathrm{Nu}$, whereas at $R e=636$, the enhancement reduces to a $10 \%$ over the bare heat sink.

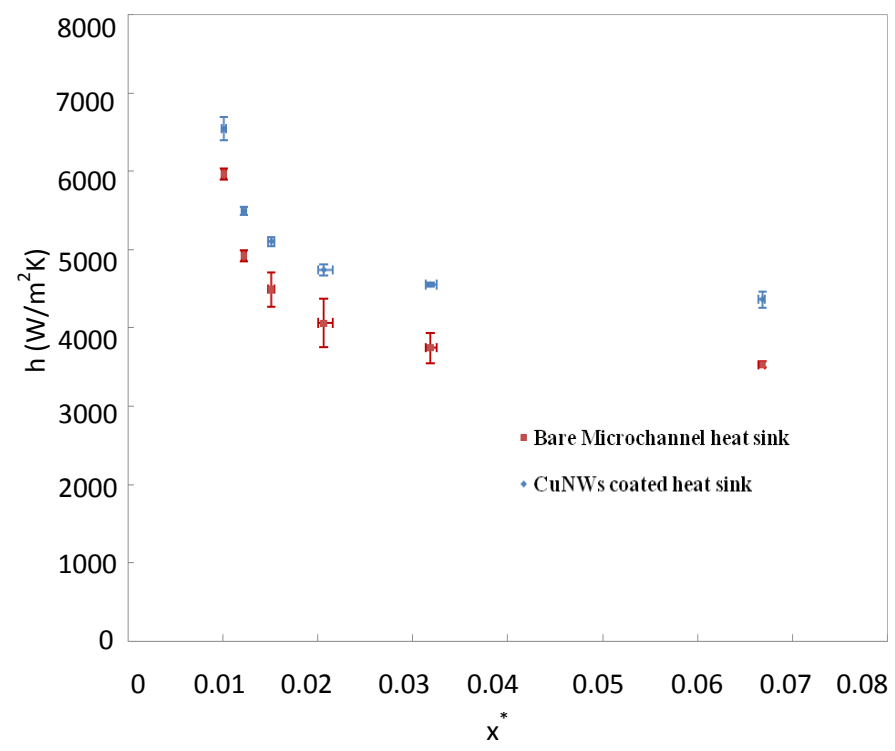

Fig. 9 Comparison of $\mathrm{h}$ as a function of $\mathrm{x}^{*}$ both for bare heat sink and CuNWs coated heat sink. Experimental findings demonstrate an increase in $\mathrm{h}$ at all $\mathrm{x}^{*}$ tested in this study.

This enhancement is possibly attributed to the enhanced heat transfer area provided by the $\mathrm{Cu}$ nanowires and improvement in surface wettability characteristics. One of the possible reasons of reduction of percentage enhancement at higher $R e$ is due to comparatively thinner boundary layer in thermally developing flow regime at higher $R e$. Another possible explanation can be borrowed from conventional fin effectiveness definition (Incorporea, F.P. et al., 2007) which implies that the fin effectiveness reduces as the heat transfer coefficient $(h)$ increases. In the test cases as the relationship between $h$ and $R e$ is proportional and almost linear (see Figure 8 and Section 3.2.2), h increases with the increase of $R e$ and hence the fin effectiveness reduces. As the assessment of surface morphology after the heat transfer experiments (more details in Section 3.4) demonstrates no notable change, the reduction in percentage enhancement at higher $R e$ has possibly no relation with surface morphology.

Comparison of average heat transfer coefficient $(\boldsymbol{h})$ The results in Figure 8 shows the variation of average heat transfer coefficient with Re for both bare and nanowires coated heat sinks. In the experimental range, it is evident that with the increase of $R e$, the value of $h$ increases linearly as expected in both cases. Since the convective heat transfer coefficient is proportional to the coolant flow 
rate and the higher $R e$ indicates higher flow rate and consequently higher $\mathrm{h}$ values. Each test case was repeated six times and the maximum standard deviation was approximately $3 \%$ at the lowest $R e=106$.

It is clear that in all test cases the $h$ values in case of CuNWs coated heat sink is higher compared to the bare heat sink in the experimental $R e$ range which confirms the improved thermal performance as observed in the form of increased $\mathrm{Nu}$ in Section 3.2.1.

In addition, the dependence of convective heat transfer coefficient, $\mathrm{h}$ on the dimensionless thermal axial distance, $x^{*}$ for both bare and CuNWs coated microchannel heat sinks are presented in Figure 9. The results in both cases show that initially $\mathrm{h}$ decreases sharply as the $x^{*}$ increases. The higher $h$ 's at low $x^{*}$ are caused by the comparatively thinner boundary layers in the developing region at higher Re. These results are in good agreement with the investigation of bare rectangular microchannels heat transfer reported earlier (Lee, P.S. et al., 2005).

Comparison of the results for bare and CuNWs coated heat sink demonstrates that for all values of $x^{*}$, the average $\mathrm{h}$ in case of CuNWs coated heat sink is higher compared to that of bare heat sink which is in harmony with the findings reported in 3.2.1.

Heat Sink Temperature The temperature distribution along the length for the bare heat sink at different $R e$ is displayed in Figure 10. As already mentioned in Section 2.2, the thermocouples are located 2.5 $\mathrm{mm}$ below from the top surface of heat sink. The locations, as measured from the inlet of the microchannel and along its length, are $4 \mathrm{~mm}, 7$ $\mathrm{mm}, 10 \mathrm{~mm}, 14 \mathrm{~mm}, 19 \mathrm{~mm}$, and $24 \mathrm{~mm}$. From the thermocouple readings, it is apparent that the temperature along the length of heat sink increases slightly as we move from upstream to the downstream for all test cases. The maximum standard deviation in temperature measurement is less than $1 \%$ at the highest $R e$. In all cases, the heat input to the cartridge heater was maintained at $\sim 13$ Watts.

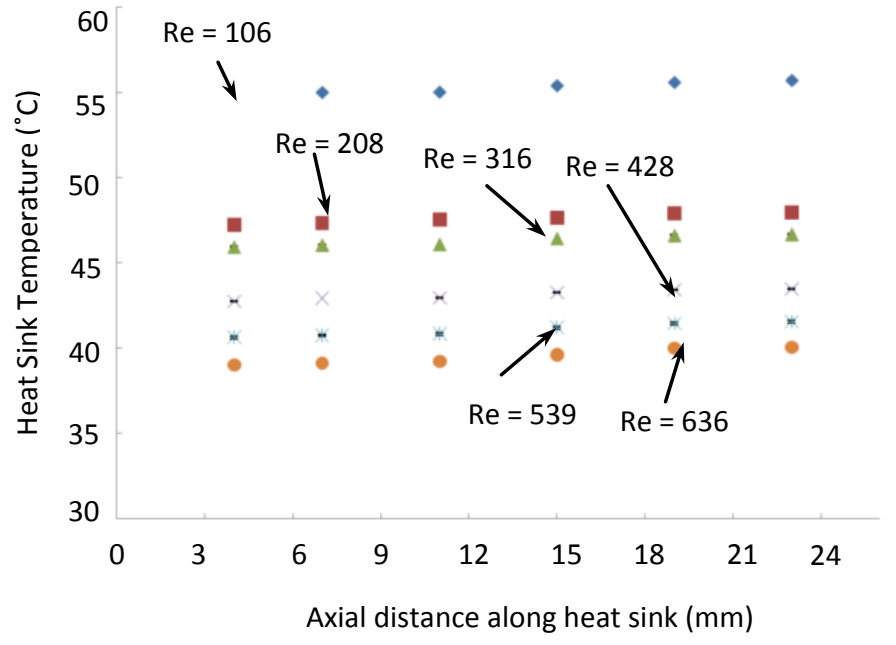

Fig. 10 Copper heat sink temperature at different thermocouple location and different Re for bare microchannel heat sink.

Figure 11 shows the comparison of copper heat sink temperature at $R e=106$ in both cases of microchannel heat sink and CuNWs coated heat sink. In both the cases, the power input to the cartridge heater was maintained at $\sim 13$ Watts. From the curves, it can be clearly observed that the CuNWs coated heat sink temperature is several degrees lower compared to bare microchannel heat sink at each thermocouple location under same power input and same flow rate. These results also confirm the superior thermal performance of the CuNWs coated heat sink compared to the bare one. Similar curves have been obtained for each Re tested.

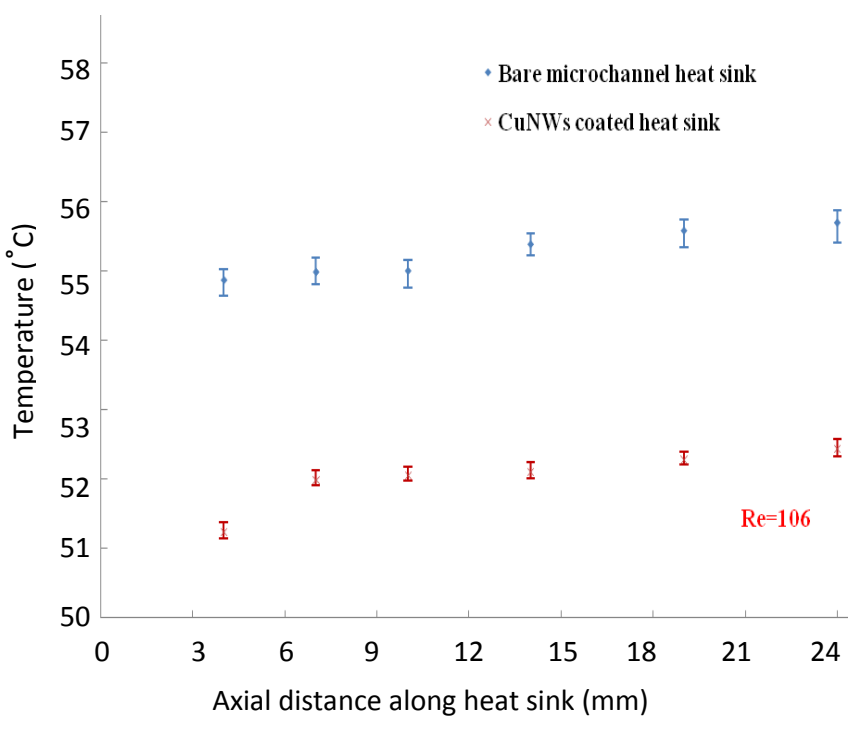

Fig. 11 Comparison of copper heat sink temperature at different thermocouple locations both for bare heat sink and CuNWs coated heat sink. Lower temperature in case of CuNWs coated heat sink indicates the enhanced thermal performance.

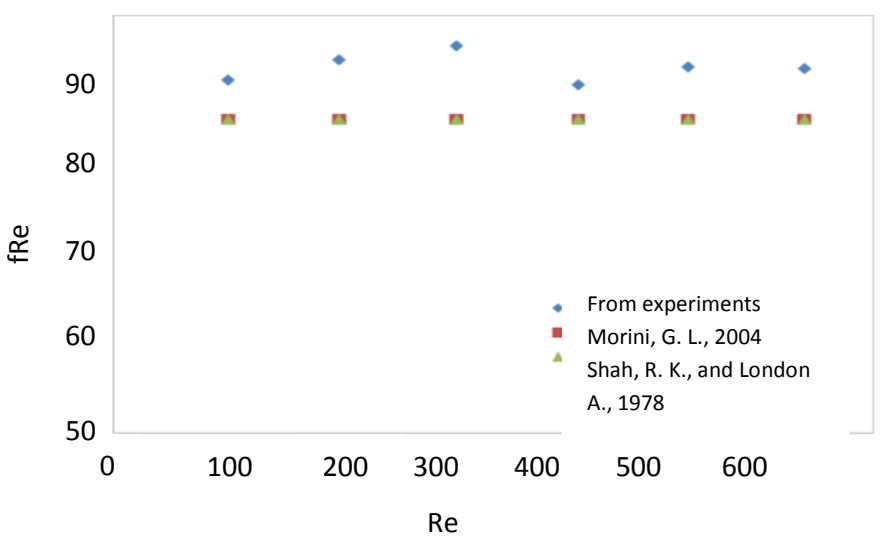

Fig.12 Poiseuille Number is plotted as a function of Re for bare microchannel heat sink. Theoretical predictions from recent microchannel work [9] and conventional scale rectangular duct [27] are also plotted for comparison.

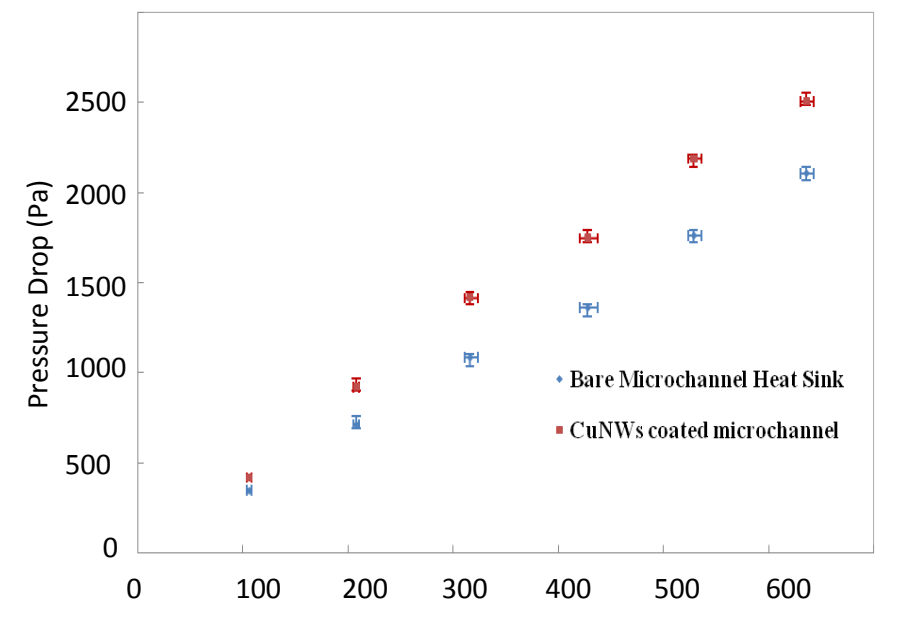

Fig. 13 Comparison of measured pressure drop with Re between bare microchannel heat sink and CuNWs coated heat sink. 


\subsection{Pressure Drop Results}

The Poiseuille Number ( $f R e$ ) for all test cases is calculated using Eq. 8 and 9 and the values are plotted against Re in Figure 12 . Prediction from recent microchannel work (Morini, G.L., 2004) and conventional rectangular duct (Shah, R.K. and London, A., 1978) are also plotted in the same figure for comparison. From the figure, it is evident that the pressure drop results are in good agreement with the theoretical predictions from both micro (Morini, G.L., 2004) and macro scale channels (Shah, R.K. and London, A., 1978). The maximum deviation is approximately $10 \%$ at $R e=308$. These results reflect the conclusion drawn from earlier microchannel works $[\mathrm{Qu}, \mathrm{W}$. and Mudawar, I., 2002; Harms, T. M. et al., 1999] that the Navier-Stokes equations can sufficiently predict the microscale flow behavior.

The comparison of measured pressure drop along with Re for both CuNWs coated heat sink and bare heat sink are shown in Figure 13. The maximum standard deviation in pressure drop measurement is approximately $6 \%$ at $R e=106$ for bare microchannel heat sink. The pressure drop at all Re for CuNWs coated heat sink increases compared to that of bare microchannel heat sink. These results are expected as the nanostructures enhance the bottom wall roughness and consequently an increase in pressure drop is observed. The percentage increase in pressure drop spans the range from $20-30 \%$ over the experimental $R e$ range with no regular trend of increasing or decreasing with the increase of $R e$. It appears that the increase in pressure drop is not a function of $R e$.

\subsection{Assessment of Surface Morphology Before and After Heat Transfer Experiments}

In order to investigate the effect of the fluid flow on $\mathrm{Cu}$ nanostructures, periodic visual inspection of the end reservoir water has been performed in all test cases. In addition to that, surface morphology of the heat sink has been investigated via SEM. The representative SEM images of the CuNWs coated heat sink after the heat transfer experiments are shown in Figure 14.

From visual inspections of the end reservoir water, there was no apparent CuNWs loss in the experimental Re range due to the shear force exerted on the CuNWs by the fluid flow.

Careful investigation of the SEM images obtained after the heat transfer experiments and comparing them with the SEM images obtained before the heat transfer experiments (see figure 6 (c) and (d)) revealed no appreciable or notable change due to the effect of fluid flow. Apparently no collapsing of the CuNWs has been found. This implies that CuNWs are robust for modification of heat transfer surface at least for single phase operation and in the experimental range reported in this study.

\section{FUTURE WORKS AND IMPROVEMENTS}

There are ample scopes of future work on extending this concept including the extension of this concept in two phase heat sinks. Another arena of future research focus can be on devising methods for the synthesis of $\mathrm{Cu}$ nanowires on high aspect ratio microchannels. Parametric analysis e.g. investigation on the effect of working fluid, exploring effect of NWs length and diameter can be an interesting work as well.

\section{CONCLUSIONS}

The objective of the present work was to determine the heat transfer rate and pressure drop in a CuNWs coated rectangular microchannel heat sink using DI water as coolant. To achieve this goal, suitable experimental facilities were designed and fabricated both for the synthesis of CuNWs on heat sink and for convective heat transfer experiments. Following the fabrication, a series of systematic experiments were conducted. The heat transfer and pressure drop results obtained with the CuNWs enhanced heat sink have been compared with those of a bare heat sink in identical condition. The experimental results demonstrate an augmentation in heat transfer performance at all Re tested. The maximum enhancement in $\mathrm{Nu}$ is as much as $24 \%$ at $R e=106$. However, the percentage enhancements of thermal performance tend to decrease with the increase of $R e$ suggesting that the proposed scheme is more effective at lower Re. The enhancement causes a penalty in pressure drop at all experimental cases investigated ranging from $20 \%-30 \%$.

To quantify the surface wettability characteristics of both bare and CuNWs coated heat sinks, static contact angle measurements of water droplet were conducted. The obtained results demonstrate an improvement in surface wettability which is in agreement with reported literature and may be one of the factors responsible for the enhanced thermal performance of $\mathrm{CuNW}$ s coated heat sink.

To explore the effect of fluid flow on the surface morphology of the nanostructures, SEM investigation was performed before and after the heat transfer experiments. The SEM images reveal no notable change in surface morphology within the experimental Reynolds Number range.

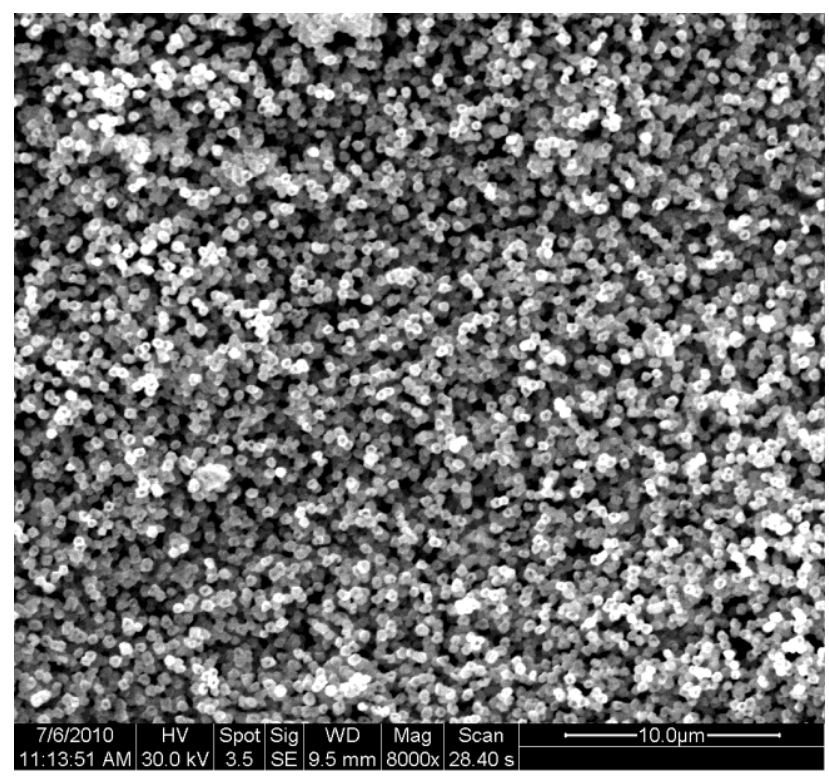

(a)

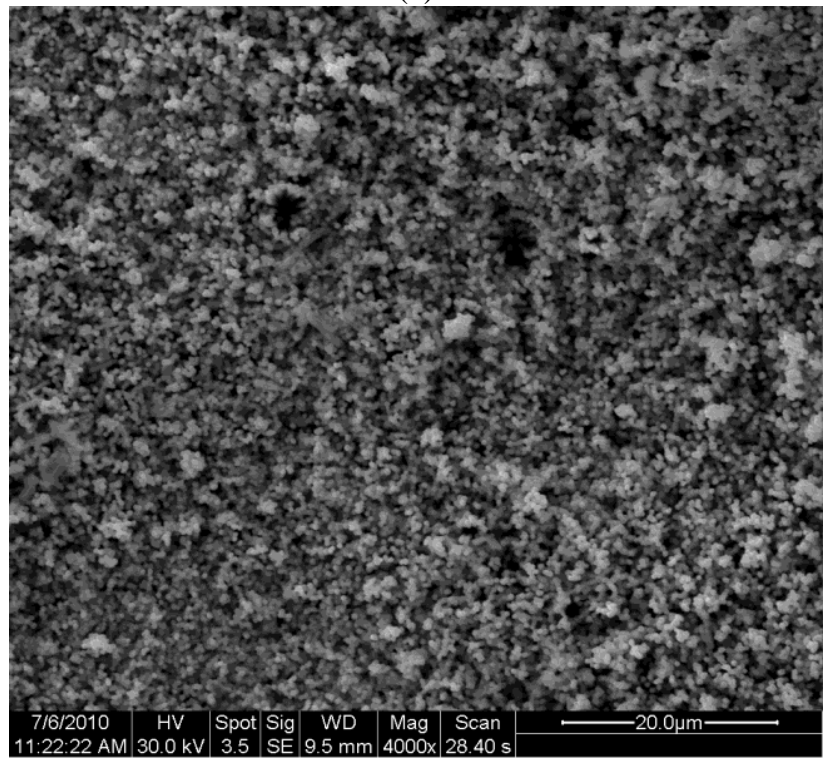

(b)

Fig. 14 (a) and (b) are representative SEM images of CuNWs coated heat sink after the heat transfer experiments respectively. 


\section{ACKNOWLEDGEMENTS}

The authors acknowledge the support of ONR (Office of Naval Research under ESRDC consortium) to J Khan and the startup funding of USC (University of South Carolina) to $\mathrm{C} \mathrm{Li}$. The authors would like to acknowledge the University of South Carolina Electron Microscopy Center for instrument use, scientific and technical assistance. The authors also thank Prof. Qian Wang and Dr. Xingjie Zan for assistance with contact angle measurements.

\section{NOMENCLATURE}

\begin{tabular}{|c|c|}
\hline$a_{i}$ & $A$ variable of functional dependence \\
\hline$A_{h t}$ & Convection Heat Transfer Area $\left(\mathrm{m}^{2}\right)$ \\
\hline$A_{c}$ & Channel cross-sectional area \\
\hline$b$ & Channel Height $(\mu \mathrm{m})$ \\
\hline$C_{p}$ & Specific Heat $\left(\mathrm{KJ} / \mathrm{Kg}^{\circ}{ }^{\circ} \mathrm{C}\right)$ \\
\hline$D_{h}$ & Hydraulic Diameter $(\mu \mathrm{m})$ \\
\hline$f$ & Friction factor (Dimensionless) \\
\hline$h$ & Convection Heat Transfer coefficient $\left(\mathrm{W} / \mathrm{m}^{2} \mathrm{k}\right)$ \\
\hline$k_{C u}$ & Thermal conductivity of copper $\left(\mathrm{W} / \mathrm{m}^{\circ} \mathrm{C}\right)$ \\
\hline$k_{f}$ & Thermal conductivity of fluid $\left(\mathrm{W} / \mathrm{m}^{\circ} \mathrm{C}\right)$ \\
\hline$L$ & Channel Length (mm) \\
\hline $\mathrm{Nu}$ & Nusselt Number (Dimensionless) \\
\hline$P$ & $\begin{array}{l}\text { Wetted perimeter }(\mathrm{mm}) \text { or Power }(\mathrm{W}) \text { or a variable of } \\
\text { functional dependence }\end{array}$ \\
\hline $\operatorname{Pr}$ & Prandtl Number (Dimensionless) \\
\hline$h$ & latent heat of phase change $(\mathrm{J} / \mathrm{kg})$ \\
\hline$k$ & thermal conductivity $(\mathrm{W} / \mathrm{m} \cdot \mathrm{K})$ \\
\hline$q$ & Heat Transfer Rate (W) \\
\hline$Q$ & Volumetric flow rate $\left(\mathrm{m}^{3} / \mathrm{s}\right)$ \\
\hline $\operatorname{Re}$ & Reynolds Number (Dimensionless) \\
\hline$s$ & Channel bottom surface to thermocouple distance (mm) \\
\hline$T$ & Temperature $\left({ }^{\circ} \mathrm{C}\right)$ \\
\hline$u_{a \mathrm{i}}$ & the uncertainty associated in the measurement of each \\
\hline & $a_{i}$ \\
\hline$U_{p}$ & the uncertainty $(\%)$ \\
\hline$v$ & Fluid velocity $(\mathrm{m} / \mathrm{s})$ \\
\hline$w$ & Channel width (mm) \\
\hline$x^{+}$ & Hydrodynamic Axial Distance (Dimensionless) \\
\hline$x^{*}$ & Thermal Axial Distance (Dimensionless) \\
\hline \multicolumn{2}{|c|}{ Greek Symbols } \\
\hline$\alpha$ & Aspect Ratio (Dimensionless) \\
\hline$\rho$ & density $\left(\mathrm{kg} / \mathrm{m}^{3}\right)$ \\
\hline
\end{tabular}

\section{REFERENCES}

Brumlik, C.J., Menon, V.P., Martin, C.R., 1994, "Template Synthesis of Metal Microtubule Ensembles Utilizing Chemical, Electrochemical and Vacuum Deposition Techniques," Journal of Materials Research 9, 1174-1183.

http://dx.doi.org/10.1557/JMR.1994.1174

Chen, R., Lu, M.C., Srinivasan V., Wang Z., Cho H.H., Majumdar A., 2009, "Nanowires for Enhanced Boiling Heat Transfer," Nano Letters, 9(2), 548-553.

http://dx.doi.org/10.1021/n18026857

Dietz, C.R., 2007, "Single Phase forced convection in a microchannel with carbon nanotubes for electronic cooling applications," M.S. Thesis, Georgia Institute of Technology, Atlanta, GA

Dixit, P., Lin, N., Miao, J., Wong, W.K., Choon, T.K., 2008, "Silicon nanopillars based 3D stacked microchannel heat sinks concept for enhanced heat dissipation applications in MEMS packaging," Sensors $\begin{array}{lcccc}\text { and Actuators } & \text { A, 141, } & \text { 685-694. }\end{array}$

Gao, T., Meng, G., Wang, Y., Sun, S., Zhang, L., 2002, "Electrochemical synthesis of copper nanowires," Journal of Physics: Condensed Matter, 14, 355-363.

http://dx.doi.org/10.1088/0953-8984/14/3/306

Garimella, S.V., 2006, "Advances in mesoscale thermal management technologies for microelectronics," Microelectronics Journal, 37(11), $1165-1185$

http://dx.doi.org/10.1016/j.mejo.2005.07.017

Garimella, S.V., Singhal, V., Liu, D., 2006, "On-Chip Thermal management with microchannel heat sinks and integrated micropumps," Proceedings of the IEEE, 94(8), 1534-1548. http://dx.doi.org/10.1109/JPROC.2006.879801

Harms, T.M., Kazmierczak, M.J., Gerner F.M., 1999, "Developing convective heat transfer in deep rectangular microchannels," International Journal of Heat and Fluid Flow, 20, 149-157. http://dx.doi.org/10.1016/S0142-727X(98)10055-3

Incorporea, F.P., Dewitt, D.P., Bergman, T.L., Lavine, A.S., 2007, Fundamentals of Heat and Mass Transfer, $6^{\text {th }}$ ed., John Wiley \& Sons, Hoboken, NJ.

Khanikar, V., Mudawar, I., Fisher, T., 2009, "Effects of carbon nanotube coating on flow boiling in a micro-channel," International Journal of Heat and Mass Transfer, 52, 3805-3817. http://dx.doi.org/10.1016/j.ijheatmasstransfer.2009.02.007

Kim, J., Bang, I.C., Buongiorno, J., Hu, L.W., 2006, "Effects of nanoparticle deposition on surface wettability influencing boiling heat transfer in nanofluids," Applied Physics Letters, 89, 153

Kline, S.J., McClintock, F.A., 1953, "Describing uncertaimties in single sample experiments," Mechanical Engineering, 75(1)

Lee, P.S., Garimella, S.V., Liu, D., 2005, "Investigation of heat transfer in rectangular microchannels," International Journal of Heat and Mass Transfer, $\quad 48, \quad 1688-1704$. http://dx.doi.org/10.1016/j.ijheatmasstransfer.2004.11.019

Li, C., Wang, Z., Wang, P.I., Peles, Y., Koratkar, N., Peterson G.P., 2008, "Nanostructured copper interfaces for enhanced boiling," Small, 4, 1084-1088. http://dx.doi.org/10.1002/smll.200700991

Lu, L., Sui, M.L. and Lu, K., 2000, "Superplastic Extensibility of Nanocrystalline Copper at Room Temperature," Science, 287, 14631466.

http://dx.doi.org/10.1126/science.287.5457.1463

Martin, C.R., 1994, "Nanomaterials: A membrane-based synthetic approach," Science, $\quad \mathbf{2 6 6 ,}$ 1961-1966. http://dx.doi.org/10.1126/science.266.5193.1961

Moore, G.E., 1965, "Cramming more components onto integrated circuits," Electronics, 38, 114-117.

Morini, G.L., 2004, "Laminar liquid flow through silicon microchannels," Journal of Fluids Engineering, 126, 485-489. http://dx.doi.org/10.1115/1.1760545

Phillips, R.J., 1987, "Forced-convection, liquid-cooled, microchannel heat sinks," Master's thesis, Massachusetts Institute of Technology, Cambridge, MA

Qu, W., Mudawar, I., 2002, "Experimental and numerical study of pressure drop and heat transfer in a single-phase micro-channel heat 
sink," International Journal of Heat and Mass Transfer, 45, 25492565.

http://dx.doi.org/10.1016/S0017-9310(01)00337-4

Shah, R.K., London, A., 1978, "Laminar flow forced convection in ducts," Adv Heat Transfer, 14, 196-220.

Singh, N., Sathyamurthy, V., Peterson, W., Arendt, J., Banerjee, D., 2010, "Flow boiling enhancement on a horizontal heater using carbon nanotube coatings," International Journal of Heat and Fluid Flow. http://dx.doi.org/10.1016/j.ijheatfluidflow.2009.11.002

Steinke, M.E., Kandlikar, S.G., 2004, "Single phase heat transfer enhancement techniques in microchannel and minichannel flows," Proceedings of International Conference on Microchannels and Minihannels, Rochester, NY, USA.

http://dx.doi.org/10.1115/ICMM2004-2328
Switzer, J.A., Shumsky, M.G. and Bohannan, E.W., 1999, "Electrodeposited Ceramic Single Crystals," Science, 284, 293-296. http://dx.doi.org/10.1126/science.284.5412.293

Tuckerman, D.B. and Pease, R.F.W., 1981, "High-performance heat sinking for VLSI," IEEE Electron Device Letters, 2, 126-129. http://dx.doi.org/10.1109/EDL.1981.25367

Vafai, K., Zhu, L., 1999, "Analysis of two layered microchannel heat sink concept in electronic cooling," International Journal of Heat and Mass Transfer, 42, 2287- 2297. http://dx.doi.org/10.1016/S0017-9310(98)00017-9

Zach, M.P., Ng, K.H. and Penner, R.M., 2000, "Molybdenum nanowires by electrodeposition," Science, 290, 2120-2123. http://dx.doi.org/10.1126/science.290.5499.2120 